\title{
The Correlation Between Arabic STUdent's ENGLISH PROFICIENCY AND THEIR COMPUTER Programming Ability at THE University LEVEL
}

\author{
Mrwan Ben Idris, Hany Ammar \\ West Virginia University, West Virginia, USA
}

\begin{abstract}
In order to find the relationship between students' English ability and the students' programming comprehension, we conducted a survey. The survey explores if students' weakness in the English language affects the ability of the students to understand the programming with respect to the following factors: Computer Lab, lecturer, mathematics, and logical thinking. This paper analyzed the results of two surveys conducted in two Libyan universities. Results of the surveys showed that 37\%, 38\%, and 25\% of students stated that their programming abilities were negatively affected by English, Computer Lab and Lecturer respectively. While over half of the lecturers mentioned that the students' lack of English was the main reason for their weak performance in understanding programming skills. This study found that the programming ability had a moderate correlation with the Level of English proficiency, $r=0.63$, for both universities. Based on English, Computer Lab and Lecturer factors, a regression model was able to explain that $45 \%$ of the variance in programming skills.
\end{abstract}

\section{KEYWORD}

Computer Programming, English language, Computer Lab, Lecturer, Logical Thinking, Mathematics.

\section{INTRODUCTION}

Complex syntactic rules, confusing structures, complex expressions and uncommon symbols for programming languages are difficult and complicated for novice programmers to interpret them quickly [1]. At the university level, learning programming for many beginner students is not easy, especially if the programming language is English based while the students are not native English speakers. Computer programming will be difficult for students who are non- native speaker because of the different issues related to understanding the language command keywords and syntax. Elazhary said that from her experience as a lecturer, she noticed that students who are not fluent in English had difficulties in learning, remembering and using conventional programming languages. Furthermore, she observed that it is even harder for them to comprehend English compilation error messages [2].

In the Middle East and North Africa, millions of people speak Arabic. Besides, many millions around the world speak Arabic because of their religions [3]. However, in Arabic countries, most of the programming courses that are offered by educational institutions are written and taught in English due to the programming languages being English based. Therefore, Arabic speaking DOI: $10.5121 /$ ijmpict.2017.8201 
students who are non-native English speakers have difficulties in understanding and remembering the commands of a programming language [4]. On the other hand, many popular programming languages such as $\mathrm{C}, \mathrm{C}++$, Java, JavaScript, and Visual Basic were developed in English speaking countries [12][4]; while just one Arabic programming language, called Phoneix Language, was developed in the Arabic language [4].

We need to develop an Arabic programming language for teaching basic programming knowledge to those who lack proficiency in the English language. Consequently, the Arabic students can use their native language to comprehend the concepts of programming and use the new Arabic Programming Language as their first step for efficiently learning programming. The new Arabic programming language will help the Arabic students to learn a programming language that was developed in their mother tongue. With the aim of supporting the development of an Arabic programming language, we conducted survey studies to find out if Arabic students that are non-native English speakers have difficulties in English programming language comprehension due to their lack of sufficient English skills [2].

The main contribution of the survey is to provide empirical evidence of the impact of the lack of English on the students' programming comprehension with respect to other factors that the percipients mentioned affect their comprehension of languages programming. Including openended questions in the survey, which allowed participants to write comments freely, will help us identify any additional factors that may affect their programming ability.

The rest of this paper is organized as follows: section 2 introduces related work, section 3 presents our problem statement, section 4 presents our empirical results, and section 5 conclusion.

\section{RELATED WORK}

Learning and teaching computer programing is not easy, and many students struggle to learn how to start with it [9]. According to Pedroni [10], learning and teaching programming is a challenge [11]. Several factors may impact students' programming ability such as previous computer programming experiences [6][8][5]. Also, the students' programming performance can be increased by implementing multiple approaches to learning the material [9]. Moreover, several studies have found a positive relation between mathematical and programming ability [5][6][7].

Undoubtedly, many factors can affect novice programmers. However, for Arabic speakers who lack English proficiency, learning from only English language programs play a significant role in such a student's performance in programming [2].

Hanan Elazhary developed Arabic versions of LISP and SQL where the syntax errors are produced in Arabic, and she tried to discover whether this Arabic software could improve the programming ability for the Arabic programmers. The participants who were from different disciplines and ages were not fluent in English. They were asked to write easy programs via the English and Arabic versions of LISP and simple queries using the English and Arabic versions of SQL after training had been done for the participants in both versions of LISP and SQL. After that, two surveys were conducted, one for experienced programmers and the other for beginner programmers. Around $98 \%$ of the beginner participants who were less than 15 years old preferred the Arabic version of LISP, and they did not show any interest in SQL. About $82 \%$ of 
International Journal of Managing Public Sector Information and Communication Technologies (IJMPICT) Vol. 9, No. 1, March 2018

the older novice programmers, who were not computer-related, preferred the Arabic version of SQL, but they did not show much interest in LISP. On the other hand, approximately $85 \%$ of the participants who had programming experience preferred the English versions of both LISP and SQL. In addition, the experienced programmers preferred improving their English language rather than using the Arabic versions [2].

Ashok and Anna analyzed the Java and SQL programming ability of non-native English students where they prepared two kinds of tests. The first test was an English language test which exams the student's ability in identifying the meaning of programming language keywords in social context. The second test was a Computer Language Test, which tests the student's ability in understanding the functional meaning of the keywords in the computer programming context. The students who are non- native English speaker were divided into two groups (student A and student B).

- Student A - learning programming courses at higher education where the instructional language is other than English.

- Student B - learning programming courses at higher education where the instructional language is English.

The authors proposed this framework for future research to identify the effect of students' English comprehension on students' programming ability [4].

However, despite the fact that a considerable amount of research has been carried out on many factors such as approaches to learning programming, and mathematics factors that affect programming performance, our paper focuses on the English language as a factor that affects the performance of Arabic speakers on the university level with respect to other factors which were stated by the participants.

\section{PROBLEM STATEMENT}

\section{Problem}

Many of the Arabic novice programmers face difficulties in understanding programming as a course, and some of them may drop the programming course after attending a few classes. Many factors may affect students' understanding of the programming course such as the labs, lecturers, Mathematics and Logical thinking involved; therefore, these factors will not be ignored in our study. However, there is another factor that can make programming harder for Arabic students which is the lack of understanding the English language.

\section{Goal}

The goal is to survey the students to explore if the students' weakness in the English language affects their ability to understand programming courses. If that survey confirms the influence of the lack of English on the programming understanding, we will try to find a solution by developing a programming language which will be Arabic to help novice students understand programming courses. 
International Journal of Managing Public Sector Information and Communication Technologies (IJMPICT) Vol. 9, No. 1, March 2018

\section{Research questions}

In our surveys, we wanted to investigate the following research questions, which could help us understand some of the Arabic students' programming problems at the university level

1. Do students' weakness in understanding English affects the ability of students to understand programming?

2. Are students' programming skills affected by other factors such as lecturers, labs, Mathematics background and logical thinking?

\section{OUR EMPIRICAL STUDY}

\section{Research Design and Instrumentation}

A cross-section survey was developed and utilized to collect data to find whether the lack of students' English proficiency leads to weakness in understanding programming. The survey consists of closed and open questions that were asked in the Arabic Language in order to be unambiguous and understandable to all Arabic students. The selected student answered the first survey. So, since most of the students did not take the TOEFL or IELTS tests beforehand, the Students were asked to rate their English language level using a 5-point Likert scale: 1 (poor), 2 (average), 3 (good), 4 (very good), and 5 (excellent). Participants also asked to mention other factors that affected their programming skills other than English Proficiency. They were also asked to indicate whether an Arabic programming language could increase their programming performance. Student programming performance is measured by their GPA in the programming course.

The second survey was answered by the lectures to take the benefit of the lecturers' experience and see if they feel that the lack of students' English leads to weakness of understanding programming. And also we tried to find out from the lecturers that there may be other potential problems affecting the students' understanding. Finally, we surveyed two universities to compare the results and avoid bias.

\section{The Pilot Study}

We conducted a pilot study for the students of Faculty of IT at the University of Benghazi. In this study $35 \%$ of the students mentioned the lecturer is a reason that affected their ability of understanding programming. Accurately $20 \%$ of students indicated that the lack lab assistance as the reason which is shown in Figure 1. We added these two factors, Lab and Lecturer, to our main factor which is the English language to avoid these two factors from affecting our results. 


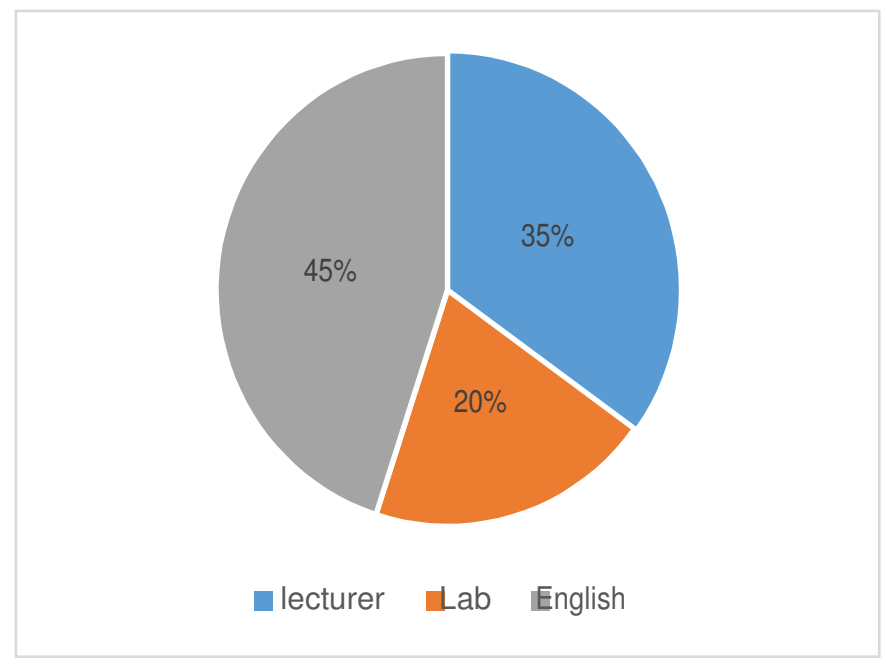

Figure. 1 The Pilot study results

\section{Our Independent and Dependents Factors}

The teachers added two new independent factors which are the Mathematics and the logical thinking. So, with the result of the pilot study, the surveys explore the effect of the five independent factors which are lecturers, labs, mathematics, the logical thinking and the English proficiency on the computer programming ability (GPA) which is our dependent variable.

\section{Participants and Data Collection}

Because we were going to investigate a limited number of undergraduate students and wanted to ensure that we included students in different years, we used stratified random sampling from the population of the two universities. The alumni students were excluded because it was difficult to communicate with them. The students were categorized into different strata based on their current year. Additionally, I included all programming lecturers who are interested in participating in the survey.

Table 1: The participants

\begin{tabular}{|c|c|c|c|c|c|}
\hline \multicolumn{3}{|c|}{$\begin{array}{c}\text { Faculty of IT } \\
\text { University of Benghazi }\end{array}$} & \multicolumn{3}{|c|}{$\begin{array}{c}\text { Department of CS } \\
\text { Omar Al-Mukhtar University }\end{array}$} \\
\hline Students & & Lecturers & Students & & Lecturers \\
\hline First year & 23 & \multirow{5}{*}{15} & First year & 15 & \multirow{5}{*}{30} \\
\hline Second year & 24 & & Second year & 18 & \\
\hline Third year & 20 & & Third year & 15 & \\
\hline Fourth year & 23 & & Fourth year & 14 & \\
\hline Fifth year & 21 & & & & \\
\hline Total & 111 & 15 & Total & 62 & 30 \\
\hline
\end{tabular}


Table 1 shows that the sample size of the students for both universities is 173 students $(\mathrm{N} 1=111+$ $\mathrm{N} 2=62)$ and for the teachers is 45 instructors $(\mathrm{N} 3=15$ and $\mathrm{N} 4=30)$. The samples $\mathrm{N} 1$ and $\mathrm{N} 3$ were taken from the students and lecturers of the Faculty of IT - the University of Benghazi while the samples N2 and N4 were taken from the students and lecturers of the Department of Computer Science - Omar Al- Mukhtar University.

\section{DATA ANALYSIS RESULTS}

Initially, the dependent variable (GPA) and the level of English proficiency were analyzed using scatter plot. A linear relationship between these two factors was found as a result. So, I choose to use linear regression method and descriptive statistics to analyze the data.

Table 2: The independent variables from the Students' point of view

\begin{tabular}{|l|c|r|}
\hline \multirow{2}{*}{$\begin{array}{l}\text { Independent } \\
\text { variables }\end{array}$} & $\begin{array}{c}\text { Faculty of IT } \\
\text { University of Benghazi }\end{array}$ & \multicolumn{2}{|c|}{$\begin{array}{c}\text { Department of CS } \\
\text { Omar Al-Mukhtar University }\end{array}$} \\
\cline { 2 - 3 } & $\mathrm{N} 1(\%)$ & $\mathrm{N} 2(\%)$ \\
\hline English & $44(40 \%)$ & $20(32 \%)$ \\
\hline Lab & $37(33 \%)$ & $29(48 \%)$ \\
\hline Lecturer & $30(27 \%)$ & $13(21 \%)$ \\
\hline \# of students & $\mathrm{N} 1=111$ & $\mathrm{~N} 2=62$ \\
\hline
\end{tabular}

As shown in Table 2, accurately $40 \%$ of the participated the University of Benghazi (N1) students indicated the English language as the first factor that had a negative impact on their GPA. The Lab and Lecturers were selected as negative factors with percentages 33\% and 27\%, respectively. On the other hand, precisely $48 \%$ of Omar Al-Mukhtar (N2) students explicitly indicated that their programming abilities were affected by the lack of labs. While $32 \%$ stated that the lack of English proficiency affected their GPA and the remaining $27 \%$ said that our programming abilities were negatively influenced by the teacher inability in giving the explanation.

From the displayed results in Table 3, the teachers (N3 and N4) were asked to rate the level of all students skills in the English language, where the rate has five levels $(1=\mathrm{Bad}, 2=$ Satisfied, $3=$ Good, 4= Very Good, and 5= Excellent). The second column describes sample 3 (N3) which is University of Benghazi's faculty members who provided their opinions in percentages. For instance, a bit more than a quarter (27\%) pointed out that students do not have enough English language skills and this could be the main reason of low GPA. The Same percentage $(27 \%)$ of sample N3 loaded the reason for having low scores among IT students in Benghazi as lack of logical thinking in the IT students. Exactly $20 \%$ of teachers mentioned that there are no enough Labs at the university, so the students could not practically practice. Precisely $13 \%$ of teachers said that students have lack of deep understanding of mathematics, and the same percentage of teachers mentioned that some of their colleagues do not provide enough information to their students in the class. In contrast, most of the teachers at Omar Al-Mukhtar University, 63\% supported the idea of students should improve their English language before starting study programming courses. Roughly the quarter of the instructors at the same university indicated that 
the university did not update most equipment and facilities at Labs. Just $7 \%$ of the teachers said that the low mathematics background of the student has a negative impact on their GPA and a relatively small percent mentioned that lecturers and logical Thinking might be the reasons.

Table 3: The Independent Variables from the Teachers' Point of View

\begin{tabular}{|l|l|r|}
\hline \multirow{2}{*}{$\begin{array}{l}\text { Independent } \\
\text { variables }\end{array}$} & \multicolumn{1}{|c|}{$\begin{array}{c}\text { Faculty of IT } \\
\text { University of Benghazi }\end{array}$} & $\begin{array}{c}\text { Department of CS } \\
\text { Omar Al-Mukhtar University }\end{array}$ \\
\cline { 2 - 3 } & $\mathrm{N} 3(\%)$ & $\mathrm{N} 4(\%)$ \\
\hline English & $4(27 \%)$ & $2(7 \%)$ \\
\hline Mathematics & $2(13 \%)$ & $1(3 \%)$ \\
\hline Logical thinking & $4(27 \%)$ & $1(3 \%)$ \\
\hline Lecturer & $2(13 \%)$ & $7(24 \%)$ \\
\hline Lab & $3(20 \%)$ & $\mathrm{N} 4=30$ \\
\hline \# of teachers & $\mathrm{N} 3=15$ & \\
\hline
\end{tabular}

As shown in figure 2 more than half of the lecturers, and $22 \%$ of the lectureres are confident that the English and the Lab showed the first and the second impact on programming skills for the students respectively. On the other hand students had selected these two factors with percentage of $37 \%$ for the English and $38 \%$ for the Lab. $25 \%$ of the students believes that their lecturers were the reason behind their lack of programming, while $7 \%$ of the lecturers agree with them. No student stated that the math and the logical thinking as factors that affected their programming understanding. $9 \%$ and $11 \%$ of the lecturers indicated that the lack of the programming caused by the weak background in math and the lack of the students' ability to think logically, respectively.

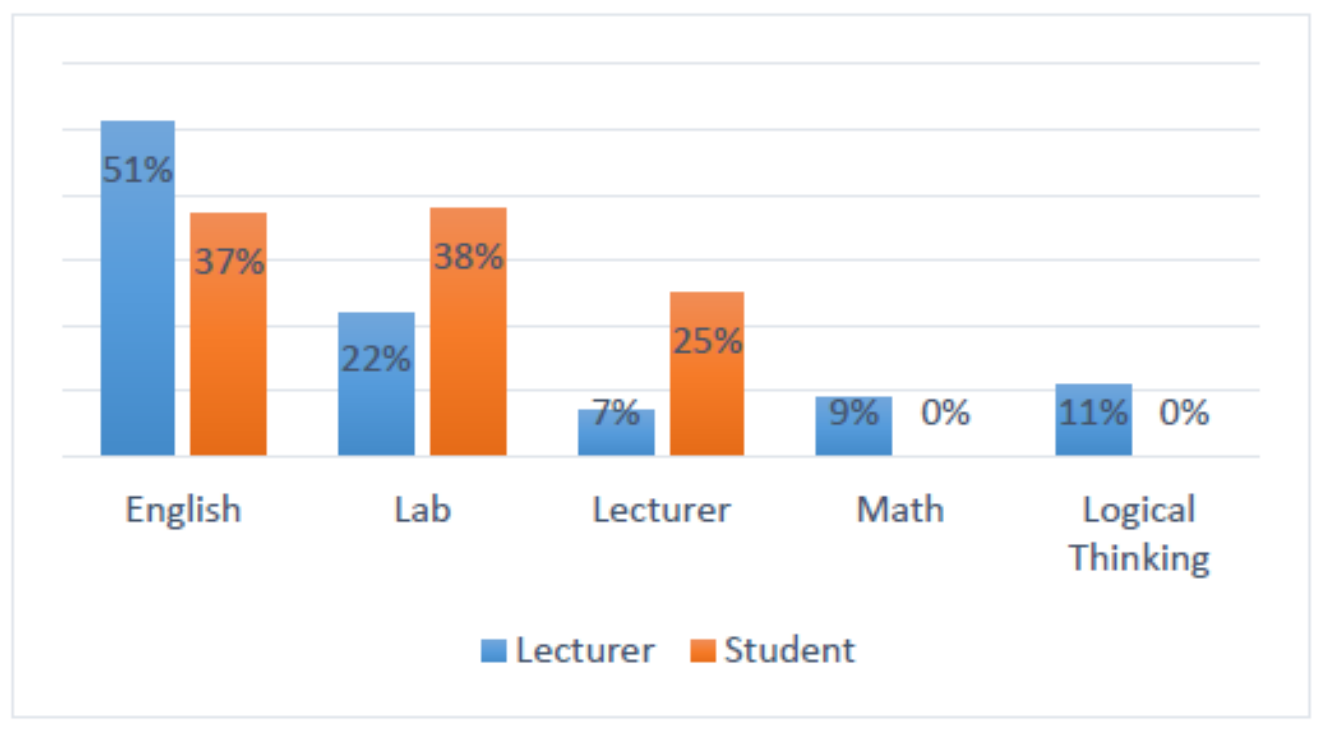

Figure. 2 The percentage of independent variables for the all samples 
International Journal of Managing Public Sector Information and Communication Technologies (IJMPICT)

Vol. 9, No. 1, March 2018

The correlation between the GPA and the level of English proficiency had been calculated, $\mathrm{r}=0.63$, which means the correlation is moderate.. However, to gain more insight of the nature of this data, a statistical regression model was designed to study the effect of the level of English Proficiency, lecturers, and labs on students' GPA at two universities, University of Benghazi and Omar Al-Mukhtar University.

Table 4a. Summary output for the regression for Faculty of IT at University of Benghazi

\begin{tabular}{lcccc}
\hline \hline & Coef. & SE & t Stat & P-v \\
\hline Intercept & & & & \\
Level of English & 0.04 & 0.25 & 8.03 & 0.00 \\
Lab & 0.33 & 0.07 & 4.87 & 0.00 \\
Lecturer & -0.67 & 0.18 & -3.74 & 0.00 \\
& -0.57 & 0.17 & -3.40 & 0.00 \\
\hline Multiple R & 0.66 & & & \\
R Square & 0.44 & & & \\
Adjusted R Square & 0.42 & & & \\
Observations & 111.00 & & \\
$F$ & 28.07 & & \\
Sig. F $F$ & 0.00 & & \\
\hline
\end{tabular}

Table $4 \mathrm{~b}$. Summary output for the regression for Dep. of CS at Omar Al-Mukhtar University

\begin{tabular}{lllll}
\hline \hline & Coef. & SE & t Stat & P-v \\
\hline Intercept & & & & \\
Level of English & 0.29 & 0.27 & 7.75 & 0.00 \\
Lab & -0.39 & 0.07 & 4.23 & 0.00 \\
Lecturer & -0.57 & 0.17 & -3.40 & 0.00 \\
\hline Multiple R & 0.67 & & & \\
R Square & 0.45 & & & \\
Adjusted R Square & 0.42 & & \\
Observations & 62.00 & & \\
$F$ & 15.52 & & \\
Sig. F & 0.00 & & \\
\end{tabular}

As shown in table $4 \mathrm{a}$ and $4 \mathrm{~b}$, the multiple regression analysis provides a significant model with some attractive results and $\mathrm{p}$-value $<0.05$. The independent value explained about $46 \%$ ( $\mathrm{R}$ Square $=0.46$ ) of the total variation in the dependent variable (GPA for N1), and around $44 \%$ (GPA for N2); where the level of English has a positive effect on GPA which means when the level of English Proficiency

increases the GPA for the student increases (Positive relationship). While, the lab and lecturer factors have a negative association with the GPA which means when the lack of labs and effort lecturers increase, the student's GPA decrease. The variation of the observed GPA (standard error) about the regression line is 0.66 .

\section{Threats to VAlidity}

1. Construct Validity: The University of Benghazi's results depend on the data that was collected during a war condition. Indeed, the university buildings were destroyed entirely, every college moved to one or more high school buildings where they study only in the evening period. These circumstances affected the new students where we found that $60 \%$ from freshman chose the lab as the first factor that influenced their programming ability.

2. Internal Validity: The teachers' sample size is considered small when applying statistical analysis methods. 
International Journal of Managing Public Sector Information and Communication Technologies (IJMPICT)

Vol. 9, No. 1, March 2018

3. Conclusion Validity: Which answered this question, have we drawn the correct conclusions? And to ensure that the right statistical methods were selected a specific care had been taken. Furthermore, in this paper, all formal statistical tests are based on random samples.

4. External Validity: It is related to the ability to generalize the results. This study is based on data collected from two universities which are from the same country. Consequently, while many of the results could be captured in any Arabic county, we cannot generalize the results because they are not based on multiple studies that have replicated the same survey in different Arabic countries.

\section{CONCluSion AND FUtURE Work}

Factors such as English, labs, lecturers, mathematical and logical thinking affected the ability of the students in programming. Descriptively, 51\% from the lecturers and $37 \%$ of the students believe that the English is the most mentioned factor that affected the students' ability in programming. While $38 \%$ of the students and $22 \%$ of the lecturers stated labs. About $45 \%$ of the variance in programming skill could be observed by the level of English proficiency, labs and lecturers. However, the student never worked with an Arabic programing language, In future, we decided to conduct an experiment using Arabic programing language, English programing language, and TOFEL or ILTS test in order to determine the level of English proficiency for the students. By testing the student we avoid any bias that related to the English language factor.

\section{ACKNOWLEDGMENT}

We show appreciation to both Mr. Khirallah Alferjani, the head of the computer science in the Faculty of IT at University of Benghazi, and Mr. Adel Fadel, the chief of the computer science at Omar Al-Mukhtar University, for helping us during the survey distribution stage by facilitating our communications with students and teachers.

\section{REFERENCES}

[1] Youssef A. Bassil, and Aziz M. Barbar, "MyProLang - My Programming Language A TemplateDriven Automatic Natural Programming Language", World Congress on Engineering and Computer Science, October 2008.

[2] Hanan Elazhary, "Facile Programming", the International Arab Journal of Information Technology, May 2012, pp. 256-261.

[3] Majdi Beseiso, Abdul Rahim Ahmad, and Roslan Ismail, “A Survey of Arabic Language Support in Semantic Web", International Journal of Computer Applications, November 2010, pp. 35-40.

[4] Ashok Kumar Veerasamy and Anna Shillabeer, "Teaching English Based Programming Courses to English Language Learners/Non-Native Speakers of English", International Proceedings of Economics Development and Research (IPEDR), 2014, pp. 17-22.

[5] Brenda Cantwell Wilson and Sharon Shrock, "Contributing to success in an introductory computer science course: A study of twelve factors, SIGCSE Technical Symposium on Computer Science Education, 2001, pp. 184-188.

[6] Byrne, P., and Lyons, G., "The effect of student attributes on success in programming", ACM 
International Journal of Managing Public Sector Information and Communication Technologies (IJMPICT)

Vol. 9, No. 1, March 2018

SIGCSE Bulletin, 2001, pp. 49-52.

[7] Bergin, S., and Reilly, R., "Programming: Factors that influence success", SIGCSE Technical Symposium on Computer Science Education, February 2005, pp. 411-415.

[8] Vennila Ramalingam, Deborah LaBelle, and Susan Wiedenbeck, "Self-efficacy and mental models in learning to program", SIGCSE conference on Innovation and technology in computer science, 2004, pp. $171-175$.

[9] Prince Yaw Owusu, Kofi Adu-Manu, John Kingsley Arthur, and Charles Adjetey, "Performance of Students in Computer Programming: Background, Field of Study and Learning Approach Paradigm", International Journal of Computer Applications, September 2013, pp. 17-21.

[10] [10]M. Pedroni (2003), "Teaching Introductory Programming with Inverted Curriculum Approach" [Online], Available: http://e-collection.ethbib.ethz.ch /eserv/eth:28338/eth-2833801.pdf (Accessed: March 21, 2011).

[11] Regina A. Garcia and Lilac A. Al-Safadi, "Comprehensive Assessment on Factors Affecting Students' Performance in Basic Computer Programming Course towards the Improvement of Teaching Techniques", International Journal for Infonomics (IJI), 2013, 682-691.

[12] From

http://www.siliconindia.com/shownews/10_Most_Popular_Programming_Languages-

siliconindia: 106520- cid-2.html. 